\title{
A FRAMEWORK FOR DESIGN COMPETENCY ASSESSMENT
}

\author{
Thandlam Sudhindra, Shravya; \\ T.M. Blessing, Lucienne
}

Singapore University of Technology and Design

\begin{abstract}
The recognition of the value of design has resulted in an increased number of programs and courses that include design and evaluate design competencies. However, there is no common reference system to (1) identify and assess the design competency of learners and the level of design competency aimed for by a course or curriculum; (2) universally recognize design competencies and competency levels. Our research goal is to identify and define distinct levels of design competency and develop a framework to help instructors, design learners, institutes as well as employers assess and/or recognize competency. This paper introduces our DesCA (Design Competency Assessment) framework and places it in the context of other frameworks. We describe how DesCA helps: (1) identify and assess design competencies associated with different design activities planned for a course or curriculum; (2) formulate learning outcomes and select appropriate competency levels, methods and tools; (3) plan and develop the design content of courses and curricula; (4) ensure curricular consistency across courses.

The vision is to make DesCA a digital platform that can serve as an international standard for design teaching, learning and curriculum development.
\end{abstract}

Keywords: Design education, Design learning, Evaluation, Competencies, Skills

\section{Contact:}

Thandlam Sudhindra, Shravya

Singapore University of Technology and Design

Engineering Product Development

Singapore

shravya_thandlam@mymail.sutd.edu.sg

Cite this article: Thandlam Sudhindra, S., T.M. Blessing, L. (2021) 'A Framework for Design Competency Assessment', in Proceedings of the International Conference on Engineering Design (ICED21), Gothenburg, Sweden, 16-20 August 2021. DOI:10.1017/pds.2021.10 


\section{INTRODUCTION}

Design education needs an overhaul. "The areas tackled by designers have greatly expanded as the creative and problem-finding-and-solving aspect of the profession has grown to encompass societal issues in a vast array of forms and emerging in countless different contexts - from redesigning procedures or organizations to tackling climate change. Design education is struggling to keep up with these changes." (Meyer and Norman, 2020) Design education is slowly but surely evolving in response to the complex nature and demands of the profession. There is a surge in the number of design schools and schools that offer design courses. In Singapore, design and design education is a government priority and the 'Design 2025 Masterplan' is geared towards 'infusing design into the nation's skillset' (DesignSingapore Council, 2016). Organizations are starting to recognize that design brings special competencies to the complex nature of work, "a rational belief based upon numerous studies that link commercial success to a design-driven approach" (Meyer and Norman, 2020).

Competency "generally describes the inner prerequisites of a person for self-organized acting, thus their willingness and ability" (Enke et al., 2015), and "the ability to" do something successfully and efficiently (Conley, 2011). It encompasses skills, knowledge, and the behaviours students need to acquire (Fass et al., 2018). Learners have different sets of design competencies, each at different levels based on their knowledge and prior experiences. We can no longer assume at university that core design concepts, skills and knowledge are new to most, if not all learners. The baseline has shifted. "The increasing number of students, their varying motivations, and their varied range of characteristics indicate that long-established pedagogical models need to be re-evaluated and reconsidered." (Pontis and van der Waarde, 2020). The goal of this research is to identify and define distinct levels of design competency and develop a framework that can help instructors, design learners, institutes as well as employers assess and/or recognize the level of an individual's design competency.

\section{BACKGROUND}

\subsection{Design in education}

Nearly two decades ago, (Rothstein 2002) wrote that "in comparison to design practice, the evolution of design education during the past couple of decades has, arguably, been less dramatic.". Although design has gained much traction since, various authors still emphasize that design education must change. (Frascara, 2017; Friedman, 2012; Norman, 2010)

Design now has a substantive role in precollege education and career preparation. It has been used in teaching mathematics, science, computer programming, music, design and technology (D\&T), and technology (Crismond and Adams, 2012). Graham (Graham, 2018) found that emerging leaders in engineering education distinguish themselves, among others, through an emphasis on engineering design. As early as 1990, Singapore adopted D\&T in secondary education, which "anchors on design action and the application of knowledge and process skills" (MOE, 2007). D\&T is compulsory for lower but remains optional for upper secondary levels (Yau and Ong, 2008). Since then, design education has become a government priority and realised through various initiatives. One of these is the 'Design 2025 Masterplan' (DesignSingapore Council 2016), recognizes the role of design in achieving the government's aims of an innovation driven economy and a loveable city. One of the five strategic thrusts is to infuse design into the nation's skillset.

\subsection{Teaching and learning}

The learning process is a "set of iterative cycles of change within the learner and between the learner and the teacher and their external environment. Each part has implications for how the teacher can assist the learner in completing those cycles of developing capability successfully." (Laurillard, 2013) She describes this as follows: The students' likely learning goals and needs in relation to the intended outcomes form the basis of how the teacher designs the teaching and learning activities and assessments. At the same time, teachers carry out their initial pedagogical design on the basis of proximal influences such as: (1) Their intended aims, learning outcomes, ambitions of how they want their students to learn and curriculum topics. (2) Their perception of the motivations, expectations, knowledge, and skills that influence the students' approach to study. (3) Any requirements set by a standards body, professional body, or quality agency, and prerequisites of knowledge and skills that are reasonable to expect of the students. (4) Level of qualification (degree) and duration of study. (Laurillard, 2013) 
In the context of design education, "the most valuable elements of the designer's perspective and process are seldom taught. Many design programs still maintain an insular perspective and an inefficient mechanism of tacit knowledge transfer". (Meyer and Norman, 2020). Weil and Mayfield emphasize that many of the competencies required to be effective in design are inherently tacit, which makes them difficult to teach especially given the various skill levels students bring (Weil and Mayfield, 2020).

\subsection{Curriculum development}

Huizinga et al. throw light on the need for significant involvement of teachers in curriculum development and the difficulties they face in doing so-such as the variation in expectations within teacher teams and the general lack of curriculum design expertise. This affects the curriculum design process and eventually the quality of the designed curriculum (Huizinga 2009 in Huizinga et al. 2014). "Teachers juggle" to foster the design learning process, while applying strategies to keep their subject matter up to date, making decisions on knowledge or skills to include, consistently aligning courses and curricula with the school's vision. (Huizinga et al., 2014)

Huizinga et al. interviewed teachers on the enacted process of designing curricula and lesson series. They found gaps in (1) curriculum design expertise, (2) pedagogical content knowledge and (3) curricular consistency expertise, and gave the following recommendations, which are very relevant to our research. These are (1) Support to enhance the quality of the curriculum design process should be offered just-in-time, so teachers can directly apply the new knowledge and skills. (2) Support should focus on the three identified gaps. (3) Templates, curricular frameworks and evaluation guidelines are essential tools to support the design of quality lesson series. (Huizinga et al., 2014)

\subsection{Competency-based education}

Time-based frameworks are common in education: "at any given time during the year the teacher is expected to be at a specific point in the textbook of course content. While not every student may progress at the same rate, the schedule typically requires everyone to move at the same rate as the teacher." This is considered "an ineffective system when the goal is to train individuals to perform specific, job-related skills." (Sullivan and McIntosh, 1996), yet "abandoning a time-based framework is a difficult innovation to implement in a university structure that is predicated on time-based education" (Gruppen et al., 2016). Competency-based education (CBE), however, has been shown to have a positive influence in various disciplines such as medicine, psychology, public affairs, and for post-graduate education in general. (Albanese et al., 2008; Chan et al., 2017; Enke et al., 2015; Getha-Taylor et al., 2013; Gruppen et al., 2016; Hurtubise and Roman, 2014; Johnstone and Soares, 2014). CBE is considered a viable alternative to traditional courses and a vehicle for rigorous assessment (Gruppen et al., 2016) suitable to "bridge the gap between the work place and post-secondary education" through a structure of stackable credentials that one has to attain (Johnstone and Soares, 2014). As a 'customizing-learning' initiative that "reorients the educational process toward demonstrated mastery and the application of knowledge and skills in the real world" (Johnstone and Soares, 2014), CBE seems fitting for design education.

Getha-Taylor et al. suggest that "competency models offer potential for defining effective and/or superior performance and then aligning curriculum and other learning opportunities with individual development goals". Their literature study indicates that competency modelling offers a number of benefits: a focus on both current and future individual, response to changing needs of the profession, help for students preparing for leadership roles, help for faculty members and administrators to respond to curriculum gaps, and design holistic educational approaches. Barriers they mention include difficulties in identifying and assessing competencies, and challenges in developing a competencybased assessment that acknowledges the differences in experiences and accomplishments of different students (Getha-Taylor et al., 2013). Competency "is not an atom but a system with several interrelated components" namely, actor (designer), tasks, situation, mission, action framework, activity and an external view of the competency. (Bonjour et al., 2007)

\subsection{Established frameworks}

Three frameworks were particularly relevant for our work: The CDIO program, Singapore's Skills Framework for Design, and the European Qualifications Framework (EQF).

The objective of the CDIO program (Crawley, 2002) is to create "rational, complete, universal and generalizable goals for undergraduate engineering education". The authors provide a template and a 
detailed step by step process (called the 12 standards for implementing the CDIO approach) to develop a syllabus as "a codification of contemporary engineering knowledge, skills and attitudes". The Implementation Kit (Ikit) and Instructor Resource material (IRMs) act as comprehensive guides with resources, teaching suggestions and assessment tools for specific learning outcomes and skill areas. (Crawley et al., 2007)

Singapore's Skills Framework for Design (SkillsFuture, 2019) is an initiative to promote skills mastery and lifelong learning in Design, Business, Innovation and Technology, and was developed by the government, together with employers, industry associations, education and training providers and unions. The Framework provides useful information on upgrading skills and career planning. The main focus of this initiative is to prepare individuals for new emerging jobs in design after leaving secondary education or when they enrol in the workforce, to find avenues to close the skills gap, and to renew, upgrade and deepen skills. The skills are categorized in 5 levels based on hierarchy and seniority in a company. E.g., the heads of all design-led teams must have level 4 or 5 expertise of all skills in the framework, whereas a designer must have a level of 2 to 4, depending on the skill and the job. This system of levels helps individuals identify competencies and plan their career.

The European Qualifications Framework is a common reference framework making qualifications in different countries more readable and understandable across different countries and systems in the Europe." (European Commission, 2008)

\subsection{Opportunity}

Many institutes offer programs and courses that include design, and evaluate design competence. Frameworks such as the above suggest competencies for discipline specific courses, programs or practicing individuals. However, we did not find a common reference system to: (1) Identify and assess the overall design competency of learners, and the level of design competency aimed for in individual courses (design courses and courses with design components) or the curriculum as a whole, and (2) Universally recognize the design competency level of an individual, course or curriculum. We are creating a new, competency-based framework for teaching, learning and assessing design that builds on existing frameworks and - we hope - can eventually be standardized.

\section{DESCA - DESIGN COMPETENCY ASSESSMENT FRAMEWORK}

\subsection{Main aims of DesCA}

The DesCA (Design Competency Assessment) framework is intended to help instructors of design and design related courses and curricula to: (1) Identify and assess design competencies associated with different design activities planned for a course or curriculum; (2) Formulate learning outcomes and select appropriate competency levels, methods and tools; (3) Plan and develop the design content of courses and curricula; (4) Ensure curricular consistency across courses.

DesCA is expected to provide a more transparent and efficient system to navigate the complexity of developing design courses and curricula.

\subsection{Target audience}

Any new system or initiative will need to take into consideration the needs and constraints of the stakeholders to make a positive impact. DesCA's primary users are the instructors as they co-create, use and interact directly with the framework. The design learners are the secondary users for whom DesCA is a guide to better understand design competency and choose relevant pathways. Design practice is an important stakeholder as their needs will have to be reflected in DesCA to ensure, ultimately, a positive impact in practice. In this paper, we will focus on design learners and instructors.

\subsubsection{Design learners}

Any academic cohort comprises a combination of learners who have different backgrounds, learning objectives and career goals. We looked into three aspects associated with being a learner: (1) Learners need to identify courses that are suitable for their chosen pathway. How might we facilitate decision making based on criteria such as: (a) knowledge of one's skills and the skills to be acquired for improved performance in the specific field; (b) understanding one's 'level' of competence with respect to the 'level' of the intended course. (2) Education systems should recognize different learners and 
cater to their needs. How might we assess and advocate design knowledge/skills (competencies) acquired by an individual with experience (personal or practice based), irrespective of their discipline? (3) Industries need to recognize competencies of different learners. How might we harmonize and present levels of design skills, attitudes, and knowledge so that they are recognizable in practice?

\subsubsection{Design Instructors}

The speed of introduction of design in education has not kept pace with the number of instructors with a design background. Moreover, design components are increasingly introduced as part of non-design courses, e.g. electrochemistry, or control engineering (Foong et al., 2017). As a result, an increasing number of instructors without design background are involved in design teaching. This contributes to the three gaps in instructor expertise Huizinga et al. identified (See Section 2.3): (1) curriculum design expertise, (2) pedagogical content knowledge, and (3) curricular consistency expertise. Based on their recommendations (Huizinga et al., 2014), our question is how might we provide tools such as templates, curricular frameworks and evaluation guidelines to support teachers in the development of courses, course components, or curricula to teach and assess design competency?

\subsection{DesCA's content and structure}

Design education revolves around the design process, usually formulated in terms of stages and steps for which methods and tools are offered. Many different processes and terms are used. The learning outcomes are expressed as skills, knowledge, attitudes etc., but assessment is often focused on the design, rather than the process. Rubrics tend to be generic to be able to assess the variety of possible designs, even for the same design brief, which makes assessment difficult and subjective. For example, a typical activity is problem formulation, and a typical related rubric refers to the quality of the problem statement. However, problem formulation demands that students investigate, recognize, examine, compare and formulate the problem, i.e., several sub-skills and knowledge are required. These sub-skills and knowledge are basic competencies that are important to learn and teach. We believe these competencies are generic. They are relevant for a variety of stages, tasks and steps in the design process, and many also play a role in non-design courses. A well-designed curriculum allows students to build up competencies through various courses. Including design components in non-design courses can strengthen the acquisition of these competencies. We further believe that when these competencies are made explicit, students will be more aware of what they learn and need to learn.

DesCA's framework intends to address this by: (1) Providing an overview of the skills and sub-skills involved in design and their link to the different objectives associated with activities and steps in the design process. (2) Helping to determine the levels of competency of the design skills a course or a curriculum aims to achieve. (3) Suggesting possible methods and tools suitable for the chosen competency level. (4) Guiding the formulation of design deliverables and learning outcomes. (5) Supporting the assessment of learning outcomes based on design competencies and deliverables.

\subsubsection{Methodology}

This paper is a summary of a Master thesis project of the first author. This preliminary work is now continued as part of a $\mathrm{PhD}$. The structure and initial content of DesCA is based on literature; the workbook, learning outcomes, rubrics and deliverables of a first year Introduction to Design course; and on the syllabus and rubrics of a final year Capstone Design course. An initial evaluation of DesCA's applicability was done by the lead instructor of Introduction to Design, who used DesCA to determine the skills, the associated tools and methods, and the expected competency levels of the course. The aim was to verify whether the proposed links between skills, competencies, tools and methods, and the introduced competency levels could be understood and used, and also to identify areas of improvement. It has to be noted that course documents do not contain these links nor levels of competency. The example in this paper is based on this course.

\subsubsection{DesCA provides an overview and a detailed breakdown of the design process.}

The basic skeleton of the DesCA framework consists of the six elements shown in Figure 1. 


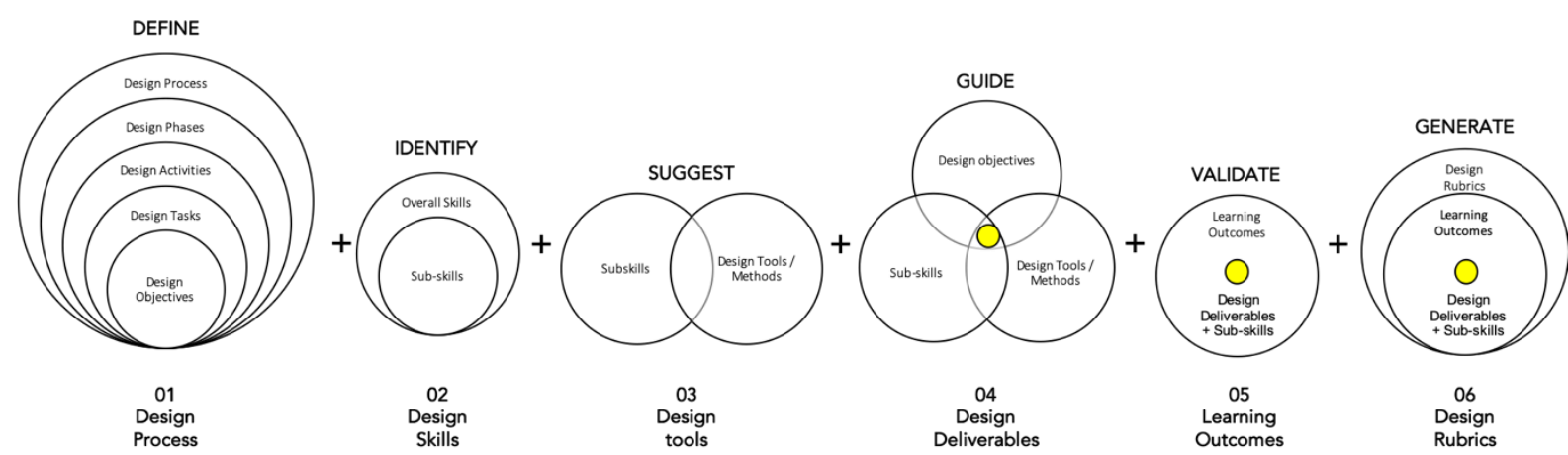

Figure 1. Components of DesCA framework

We consider these elements fundamental for design education: (1) A model of the design processcomprising design phases, activities, tasks and objectives. (2) Skills-needed to achieve the objectives and specified as "prerequisite" or "to be acquired". (3) Tools and methods-to be taught or made available to learn certain skills and aid the design process. (4) Design deliverables - the output of a task or step, i.e. the 'visible manifestation' resulting from applying certain skills using certain tools for specific design objectives. These are the basis for the assessment and can take many different forms and hence may require different assessment methods. (5) Learning outcomes-measurable criteria with respect to the deliverables, and, (6) Design evaluation rubrics - the criteria to assess deliverables and competencies for the purpose of grading and/or enhancing learning by identifying scope for improvement.

The UK Council's double diamond design process - Discover, Define, Develop, Deliver - used at SUTD (Telenko et al., 2015) forms the main design phases in DesCA. As shown in Table 2, the phases involve design activities (Lawson and Dorst, 2013), which in turn involve design tasks (Crismond and Adams, 2012) that are facilitated by design exercises. Each task has specific objectives (Lawson and Dorst, 2013). While design phases can have different names and differ in number, design activities and tasks tend to be very similar. The focus is therefore on the latter. DesCA will accommodate for changes in the phases and tasks, for changes in terminology, and for moving tasks, objectives and skills for a particular course or curriculum, while still providing a comprehensive structure to facilitate the planning of the course or curriculum.

\subsubsection{DesCA links skills to different objectives associated with the design process.}

The skills identified in literature (Shah, 2005; SkillsFuture, 2019) are linked to tasks (Table 2). The set of skills shown is still under development. Depending on the course, curriculum or personal preference of the design instructor, a subset of phases, tasks and skills that are considered relevant can be selected.

\subsubsection{DesCA suggests possible methods and tools based on the determined competency level.}

Many websites, books and card sets exist that describe design methods and tools, such as 'TheDesignExchange' (TDX) of UC Berkeley (https://www.thedesignexchange.org). Due to time constraints only very few can be taught. Often the most popular ones are chosen, even though they may not always contribute to obtaining the desired competencies. Portals such as TDX provide educators and practitioners with an extensive library of methods, searchable based on process phases, overall skills, and method features, such as duration or people involved. DesCA aims to link method and tool descriptions to the detailed set of DesCA skills and sub-skills, as well as to tasks and competency levels (see Table 2).

\subsubsection{DesCA assists with determining the competencies and levels of competency a course aims to achieve.}

DesCA prompts instructors to indicate the 'expected competency levels' for the selected skills, from [1] (low) to [5] (high). The "Learning Expectations and Outcomes (LEO)" matrix (see Table 1) was developed with course leads at SUTD to provide initial criteria for levels [1], [3] and [5]. LEO helps instructors determine the skills to be taught or honed, and plan lessons accordingly. 
Table 1. An extract from the initial learning expectations and outcomes (LEO) matrix

\begin{tabular}{|c|l|c|l|c|c|}
\hline \multirow{2}{*}{$\begin{array}{c}\text { List of } \\
\text { skills }\end{array}$} & \multicolumn{2}{|c|}{ Learning Expectations \& Outcomes (LEO) for Expected Competency Levels (CL) of skills } \\
\cline { 2 - 6 } & \multicolumn{1}{|c|}{$\mathbf{1}$} & $\mathbf{2}$ & \multicolumn{1}{|c|}{$\mathbf{3}$} & $\mathbf{4}$ \\
\hline Empathy & $\begin{array}{l}\text { Can empathize with users that } \\
\text { are not very different from } \\
\text { him/her/them. }\end{array}$ & $\begin{array}{l}\text { Can partially empathise } \\
\text { with a user, for some } \\
\text { common contexts and } \\
\text { situations. }\end{array}$ & $\begin{array}{l}\text { Can fully empathise with the } \\
\text { user and other stakeholders, } \\
\text { and completely understand } \\
\text { what their needs are. }\end{array}$ \\
\hline $\begin{array}{l}\text { Analytical } \\
\text { thinking }\end{array}$ & $\begin{array}{l}\text { Able to analyse a particular } \\
\text { problem/situation from some } \\
\text { angles, with limited data. }\end{array}$ & $\begin{array}{l}\text { Able to analyse a } \\
\text { particular } \\
\text { problem/situation from } \\
\text { most angles, with limited } \\
\text { data. }\end{array}$ & $\begin{array}{l}\text { Able to analyse a particular } \\
\text { problem/situation from all } \\
\text { angles, taking into account } \\
\text { as much data as possible. }\end{array}$ \\
\hline
\end{tabular}

The LEO matrix is not a grading rubric. The chosen competency level will represent the highest score in the grading rubric, as this is the level to be achieved. For example, when - using the LEO matrix the chosen "empathy" level is 3, lessons will have to be planned to develop empathy with a user, at least for some common contexts and situations (see Table 1). If students achieve this, they will obtain the highest mark for this rubric: for a grading scheme using A-E, this would translate to an A. Had the chosen competency level been 5, we would expect students to have included other stakeholders and situations before achieving an A.

Table 2 shows the application of the LEO matrix for the Introduction to Design course. The desired competency levels for the different sub-skills can be found in the middle of the matrix. An A-grade for a sub-skill (in the one but last one column), reflects the achievement of the chosen competency level. The full set of criteria for the different levels will be developed with reference to other established frameworks such as the CDIO 5-point scale for knowledge and skills (Crawley et al., 2007) and the Skills Framework's system of levels (SkillsFuture, 2019).

Design courses often involve multiple instructors, only few of whom might have been involved in the design of the course. Setting expectations by determining the 'expected competency level' is expected to create consistency in teaching and assessment across the team of instructors. Furthermore, programs will have several courses that address similar skills. The LEO matrix helps understand the level of competency aimed for in a course in comparison to other courses, and ensures that courses in a program build on each other and together achieve the competency levels expected of the graduating students.

\subsubsection{DesCA guides formulation of design deliverables and related learning outcomes.}

The framework provides a structure of activities, tasks, objectives, skills, relevant methods, and competency expectations which helps the formulation of suitable deliverables, learning outcomes, lesson plans and supporting material for the course (or curriculum). Assessment is usually based on deliverables at certain points in time (time-based curriculum). We consider it critical to take into consideration other visible manifestations as deliverables and learning outcome, that showcase the use of knowledge, skills, tools, methods, etc, and their progress along the different stages of the design process in order to provide feedback and enhance the learning process. We see an important synthesis with CDIO's comprehensive process for developing meaningful learning outcomes.

\subsubsection{DesCA supports the assessment of learning outcomes based on skills and deliverables.}

Typically, assessment happens throughout a course. Usually, intermediate and final design deliverables, as well as their observed participation act as a medium to assess a student's learning. These assessments are subjective. With DesCA, we add one more layer to assessing design deliverables-Skills. When preparing a course, the following questions are important. (1) Does the list of deliverables provide room to display the expected set of skills? DesCA's transparent format urges instructors to take essential skills into consideration when determining deliverables, i.e. DesCA imparts pedagogical content knowledge. (2) What skills is the learner expected to use to realize these deliverables? The DesCA framework requires instructors to select all skills associated with the chosen tasks and phases in the design process. This will help them remain cognitive of the skills a learner must be using. (3) What is the extent of the skills used by the learner? DesCA prompts instructors to determine the desired competency level and to translate this into an assessment rubric (using the LEO matrix). Table 2 showcases an example of the results of using the DesCA framework by the lead of the Introduction to Design course. Based on the 
expected competency levels associated with the skills, DesCA generates two grading rubrics (for skills and for design deliverables) to assess and evaluate students.

Table 2. The initial design competency assessment framework

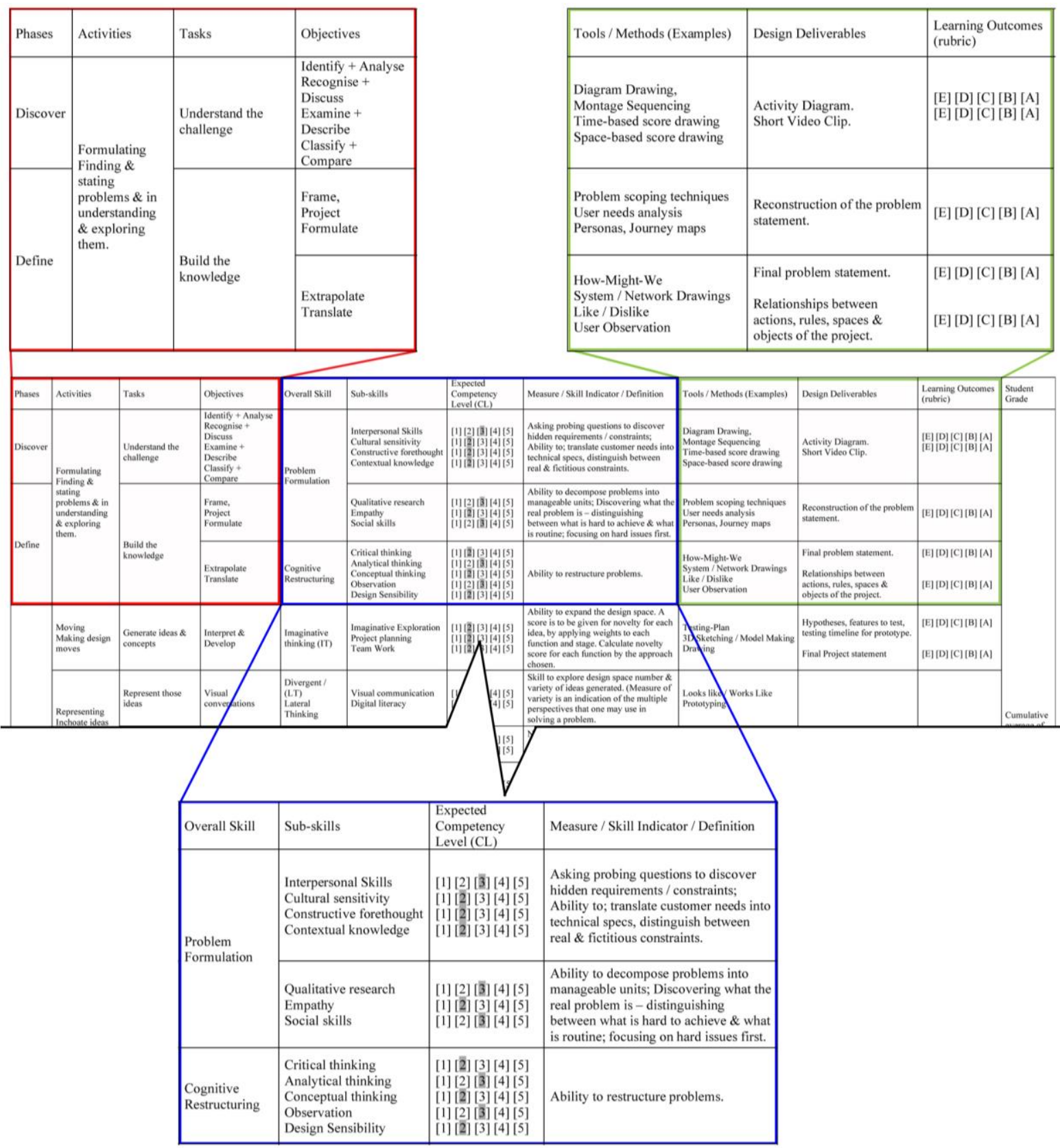

\subsection{The DesCA Tool}

Designing a curriculum or a course can be challenging with so many elements that need to be integrated. DesCA simplifies the process by providing a structure to guide the instructor through the process of designing courses and curricula. One of the objectives is to make DesCA a highly interactive digital platform to support this process and provide prompts and suggestions. As an online platform, DesCA can also offer updates in the form of new design tools suggested by research for a certain task or new skills needed in the industry that can be useful in keeping the curriculum up to date.

\subsection{Evaluation}

DesCA is designed to be flexible, offering the user (curriculum developers and instructors) the freedom to design or adapt their course content and assessment to meet the expected standard or 
levels, and adapt the framework content to their particular context. This means that lesson plans, tests or assessments and grading can be devised according to the goals of the instructors or institution, while DesCA adds value by encouraging instructors to clearly define this content through the framework.

As mentioned earlier, an initial evaluation of DesCA was undertaken by the Lead of Introduction to Design to verify whether the proposed links between skills, competencies, tools and methods, as well as the introduced levels, could be understood and used. He was indeed able to use DesCA to determine the skills, the associated tools and methods, and the expected competency levels of the course. The evaluation also gave rise to additions and modifications of the framework.

We are currently evaluating DesCA for use in the first-year course 'Modelling and Analysis' in which the instructors want to include design components.

\section{CONCLUSION}

\subsection{Summary}

In this paper we identify common problems faced in recognizing and assessing design competencies in education based on literature and our own experiences and observations in design education. Despite initiatives (government and private) aimed at increasing design competency (skills, knowledge, mindsets, etc), assessing design competency remains a challenge and established levels of competency are lacking. Taking into consideration the factors that influence the teaching, learning and curriculum development experience in K-20 education we developed of the DesCA (Design Competency Assessment) framework for an effective competency-based design education. DesCA defines activities and steps in a design process, identifies related design skills and sub-skills, allows determining competency levels for selected skills, suggests design tools and methods, guides the formulation of design deliverables and the learning outcomes, and supports assessment by generating comprehensive evaluation rubrics for both skills and deliverables.

\subsection{Vision}

The vision is to make DesCA a digital platform that can serve as an international standard for design teaching, curriculum development, and design learning, similar to the role of TOEFL / IELTS for English language, Trinity London for music and the Bologna Process for higher education systems across Europe. We imagine this platform to link to or integrate other relevant

\subsection{Scope for improvement and future research}

The current version of DesCA is a first prototype to verify its structure for the context of design courses in post-secondary education only. The included skills, sub-skills, processes and tools/methods do not constitute a comprehensive set and it is not yet clear where to set the boundaries. The most appropriate number of levels of design competency (currently 5) needs to be verified. The use for courses in which only certain design components and skills are integrated need to be verified too.

Further research is required to address (1) Define the term "competency" in the context of design education as various authors consider different components of a competence. (2) Include other levels of education (primary, secondary and professional); (3) Consider the latent needs, requirements and design practices of both design instructors and design learners; (4) Understand the impact of differences in teaching and learning related to age, background, education, skill sets, work experience, personal and professional goals, etc. (5) Build upon or integrate other existing frameworks, programs and processes. These and further topics will provide valuable insights for the improvement, introduction and use of the framework, such as best practices in design education, course profiles, learner profiles, design competencies and competency levels that are in use, design skills and tools associated with these competency levels and finally, guidelines for the creation of effective curricula.

\section{REFERENCES}

Albanese, M.A., Mejicano, G., Mullan, P., Kokotailo, P. and Gruppen, L. (2008), "Defining characteristics of educational competencies", Medical Education, John Wiley \& Sons, Ltd, Vol. 42 No. 3, pp. 248-255.

Bonjour, E., Micaëlli, J.-P., Hlaoittinun, O. and Deniaud, I. (2007), "Design and core competency, the missing links”, IFAC Proceedings Volumes, Elsevier BV, Vol. 40 No. 18, pp. 49-53. 
Chan, C.K.Y., Fong, E.T.Y., Luk, L.Y.Y. and Ho, R. (2017), “A review of literature on challenges in the development and implementation of generic competencies in higher education curriculum", International Journal of Educational Development, Elsevier Ltd, Vol. 57, pp. 1-10.

Conley, C. (2011), "The Core Competencies of Design: The Basis of a Broadly Applicable Discipline", Idsa.Org, pp. 7-11.

Crawley, E.F. (2002), "Creating the CDIO syllabus, a universal template for engineering education", 32nd Annual Frontiers in Education, Boston, MA, USA, pp. F3F-F3F.

Crawley, E.F., Malmqvist, J., Östlund, S. and Brodeur, D.R. (2007), Rethinking Engineering Education: The CDIO Approach, Rethinking Engineering Education: The CDIO Approach, Springer, Boston MA

Crismond, D.P. and Adams, R.S. (2012), "The informed design teaching and learning matrix", Journal of Engineering Education, Vol. 101 No. 4, pp. 738-797.

DesignSingapore Council. (2016), Design 2025, Singapore.

Enke, J., Kraft, K. and Metternich, J. (2015), “Competency-oriented design of learning modules", Procedia CIRP, Vol. 32, Elsevier B.V., pp. 7-12.

European Commission. (2008), “The Bologna Process and the European Higher Education Area | Education and Training”, available at: https://ec.europa.eu/education/policies/higher-education/bologna-process-andeuropean-higher-education-area_en (accessed 1 August 2020).

Fass, J., Rutgers, J. and Chui, M.-L. (2018), "Using Design Competencies to Define Curricula and Support Learners", DRS2018: Catalyst, Vol. 7, available at:https://doi.org/10.21606/drs.2018.578.

Foong, S., Subburaj, K. and Wood, K.L. (2017), “An Inductive, Design-Centric Approach to Control Engineering Education With a Competitive Atmosphere", Proceedings of the ASME 2017 Dynamic Systems and Control Conference, DSCC2017 October 11-13, Tysons, Virginia, USA DSCC2017-5157

Frascara, J. (2017), "Design, and design education: How can they get together?", Art, Design \& Communication in Higher Education, Vol. 16 No. 1, pp. 125-131.

Friedman, K. (2012), "Models of Design: Envisioning a Future Design Education”, Visibile Language, Vol. 46 No. 1(2), pp. 132-153.

Getha-Taylor, H., Hummert, R., Nalbandian, J. and Silvia, C. (2013), "Competency Model Design and Assessment: Findings and Future Directions", J. of Public Affairs Education, Vol. 19 No. 1, pp. $141-171$.

Graham, R. (2018), The Global State of the Art in Engineering Education, Mit.

Gruppen, L.D., Burkhardt, J.C., Fitzgerald, J.T., Funnell, M., Haftel, H.M., Lypson, M.L., Mullan, P.B., et al. (2016), "Competency-based education: programme design and challenges to implementation", Medical Education, Vol. 50 No. 5, pp. 532-539.

Huizinga, T., Handelzalts, A., Nieveen, N., and Voogt, J.M. (2014), "Teacher involvement in curriculum design: Need for support to enhance teachers' design expertise", J. of Curriculum Studies, Vol. 46 (1), pp. 33-57.

Hurtubise, L. and Roman, B. (2014), "Competency-Based Curricular Design to Encourage Significant Learning”, Current Problems in Pediatric and Adolescent Health Care, Vol. 44 No. 6, pp. 164-169.

Johnstone, S.M. and Soares, L. (2014), "Principles for Developing Competency-Based Education Programs", Change: The Magazine of Higher Learning, Vol. 46 No. 2, pp. 12-19.

Laurillard, D. (2013), Teaching as a Design Science, Teaching as a Design Science, Routledge.

Lawson, B. and Dorst, K. (2013), Design Expertise, Design Expertise, Taylor and Francis.

Meyer, M.W. and Norman, D. (2020), "Changing Design Education for the 21st Century", She Ji, Elsevier, Vol. 6 No. 1, pp. 13-49.

MOE. (2007), Design \& Technology Syllabus, available at: https://www.moe.gov.sg/docs/defaultsource/document/education/syllabuses/sciences/files/design-and-technology-lower-secondary-2007.pdf.

Norman, D. (2010), "Why Design Education Must Change", Core77, available at: https://www.core77.com/posts/17993/why-design-education-must-change-17993

Pontis, S. and van der Waarde, K. (2020), "Looking for Alternatives: Challenging Assumptions in Design Education”, She Ji, Tongji University Press, Vol. 6 No. 2, pp. 228-253.

Shah, J.J. (2005), "Identification, measurement \& development of design skills in engineering education", Proceedings ICED 05, the 15th International Conference on Engineering Design, Vol. DS 35, pp. 1-15.

SkillsFuture. (2019), Skills Framework for Design - A Guide to Occupations and Skills, Singapore, available at: https://www.skillsfuture.gov.sg/.

Sullivan, R. and McIntosh, N. (1996), "The competency-based approach to training”, Medical Journal of Indonesia, Faculty of Medicine, Universitas Indonesia, Vol. 5 No. 2, pp. 95-98.

Telenko, C., Elara, R., Pey, L., Telenko, C., Wood, K., Otto, K., et al. (2015), "Designettes: An Approach to Multidisciplinary Engineering Design Education”, J. of Mechanical Design, Vol. 138 No. 2, p. 22001.

Weil, D. and Mayfield, M. (2020), "Tomorrow's critical design competencies: Building a course system for $21 \mathrm{st}$ century designers", She Ji, Elsevier, Vol. 6 No. 2, pp. 157-169.

Yau, C. and Ong, C. (2008), "Pupils' views towards design and technology in Singapore”, Design and Technology Education: An International Journal, Vol. 10 No. 3, pp. 37-49. 